Artigo Original

\title{
Atividade antimicrobiana de extratos de Ilex paraguariensis
}

\author{
Antimicrobial activity of Ilex paraguariensis extracts \\ Júlia Oliveira Penteado ${ }^{1}$, Lisiane Martins Volcão ${ }^{1}$, Daniela Fernandes Ramos ${ }^{1}$, Flávio \\ Manoel da Silva-Júnior ${ }^{1}$, Ana Luiza Muccillo-Baisch ${ }^{1}$. \\ ${ }^{1}$ Universidade Federal de Rio Grande, Rio Grande, RS, Brasil.
}

Submissão: 26/09/2016

Aceite: $03 / 10 / 2016$

julia-penteado@hotmail.com

\section{RESUMO}

JUSTIFICATIVA E OBJETIVO: A Ilex paraguariensis St. Hilaire é conhecida popularmente como mate ou erva-mate, consumida popularmente no sul do Brasil, Paraguai e Argentina. Estudos têm evidenciado atividades bioativas da Ilex paraguariensis, como a atividade antioxidante, antinflamatória, diurética, digestiva, cicatricial e estimulante, conferindo um potencial terapêutico à mesma. Tais atividades bioativas da Ilex paraguariensis podem estar relacionadas com os compostos presentes na planta. Como exemplo a presença de polifenóis, flavonoides, xantinas, aminoácidos, vitaminas e minerais. Devido às informações contraditórias sobre os compostos das plantas que contribuem para a atividade antimicrobiana, o presente trabalho teve por objetivo determinar o potencial antimicrobiano dos extratos hexânico, metanólico e aquoso de Ilex paraguariensis, frente as bactérias gram-positivas e gram-negativas. METODOLOGIA: Para avaliação da atividade antimicrobiana foi realizada a técnica de microdiluição em caldo, frente às cepas Staphylococcus aureus (ATCC 12598), Klebsiella pneumoniae (ATCC 700603), Acinetobacter baumannii (ATCC 19606) e Pseudomonas aeruginosa (ATCC 15442). RESULTADOS: A atividade antimicrobiana de Ilex paraguariensis foi demonstrada pelo extrato hexânico e aquoso nos quais apresentaram atividade antimicrobiana frente a todos os microrganismos estudados. Sendo que, a melhor inibição para o extrato aquoso CMI $=25 \mu \mathrm{g} / \mathrm{mL}$ foi frente ao Staphylococcus aureus, enquanto para o extrato hexanico a CMI $100 \mu \mathrm{g} / \mathrm{mL}$ para a Acinetobacter baumannii. CONCLUSÃO: Portanto, a Ilex paraguariensis é uma fonte de pesquisa para novos agentes antimicrobianos naturais. Estes extratos são possíveis candidatos cuja atividade antimicrobiana poderá contribuir para o tratamento de doenças infecciosas causadas tanto por bactérias gram-positivas quanto negativas.

DESCRITORES: Ilex paraguariensis. Bactérias. Produtos naturais. 


\section{INTRODUÇÃO}

A Ilex paraguariensis A. St. - Hil (Aquifoleaceae) é uma espécie vegetal e suas folhas secas e moídas são utilizadas no preparo de uma bebida peculiar, consumida por parte da população da América do Sul ${ }^{1}$. Nos países onde é consumida recebe diferentes denominações, sendo "chimarrão" no Sul do Brasil, "mate" na Argentina e Uruguai e "tererê" no Paraguai ${ }^{2}$. Mais recentemente, está crescendo em popularidade nos Estados Unidos como um ingrediente alimentar ou em suplementos alimentares ${ }^{3,4}$.

Alguns estudos indicam que os derivados de IIex paraguariensis possuem diversas propriedades benéficas, tais como atividade antioxidante, antitumoral, diurética, digestiva, cicatricial e estimulante, conferindo um grande potencial terapêutico a mesma ${ }^{5}$. Estas bioatividades estão relacionadas com a presença de diferentes classes de compostos fenólicos, principalmente, ácido gálico, ácido siríngico, ácido cafeico, ferúlico e $\rho$-cumárico, quercetina, rutina e metilxantinas ${ }^{6}$.

A pesquisa com substâncias naturais, como as plantas, tem se tornado um indicativo medicinal, isto devido às propriedades farmacológicas já relatadas, como atividades antioxidante, antitumoral, antiinflamatória e antimicrobiana ${ }^{7-9}$. O uso medicinal das plantas pode ser explicado devido à diversidade dos compostos e a estrutura complexa das plantas que podem agir em sinergismo com outras substâncias ${ }^{10}$. Em particular, as plantas demonstram a vantagem de mimetizar os efeitos secundários associadas ao tratamento de antimicrobianos convencionais ${ }^{11-12}$.

O sucesso do uso de qualquer agente terapêutico é comprometido com o desenvolvimento de resistência do agente ao composto a partir do momento no qual é empregado. Isto se aplica para agentes utilizados no tratamento de infecções bacterianas, fúngicas, parasitárias, virais e para o tratamento de doenças crônicas como o câncer e diabetes ${ }^{13}$.

No caso específico de agentes antimicrobianos, esta situação tem sido agravada por um aumento do desenvolvimento de resistência por diferentes microrganismos, incluindo bactérias e parasitas, e o custo elevado de agentes antimicrobianos ${ }^{14}$. O aumento da prevalência das bactérias multirresistentes e com dose dependente dos antibióticos denota a situação direta de morbidade e mortalidade. Logo, se busca novas estratégias de combate a infecção ${ }^{15}$. O desenvolvimento de novos fármacos, eficientes e de baixo custo é, portanto, de grande importância. 
Nos últimos anos, poucos estudos têm sido realizados a fim de evidenciar a relação do potencial antimicrobiano de Ilex paraguariensis com os espectros de bactérias gram-positivas e gram-negativas ${ }^{14,14,17}$. Existem informações contraditórias sobre quais os compostos das plantas podem contribuir para a atividade antimicrobiana e, se estes compostos, podem ter efeito bactericida ou sinérgico quando utilizados em combinação ${ }^{4}$.

Diante do exposto, o objetivo deste trabalho foi avaliar a atividade antimicrobiana do extrato de Ilex paraguariensis frente a quatro bactérias de interesse clínico.

\section{MÉTODOS}

\section{Caracterização e preparo da amostra}

A Ilex paraguariensis foi adquirida localmente a partir do comércio da cidade de Rio Grande, Rio Grande do Sul, Brasil. Os extratos foram obtidos por banho de ultrassom usando o modelo Ultronique Q3.0/40A em frequência de $40 \mathrm{Khz}$, por 20 minutos. Após, a filtragem dos extratos foi realizada utilizando papel filtro $12,5 \mu \mathrm{m}$.

Os extratos foram evaporados por liofilização a vácuo (SPD1010-115 speed vac (B Thermo savant) em frequência $50 / 60 \mathrm{~Hz}$ e mantidos sob refrigeração. Para os ensaios, os extratos foram dissolvidos em DMSO $10 \mathrm{mg} / \mathrm{mL}-200 \mu \mathrm{g} / \mathrm{mL}$.

\section{Avaliação da atividade antimicrobiana}

Para o estudo foram avaliados os extratos de Ilex paraguariensis através do método de microdiluição em caldo de acordo com CLSI (2012), conforme descrito: foram adicionados $50 \mu \mathrm{L}$ de caldo Muller Hinton e $50 \mu \mathrm{L}$ de cada extrato de Ilex paraguariensis, realizada a microdiluição 1:2 de maneira a testar os extratos nas concentrações de 200 a 0,390 $\mu \mathrm{g} / \mathrm{mL}$. Após foram adicionados $50 \mu \mathrm{L}$ de inóculo de Staphylococcus aureus (ATCC 00022), Klebsiella pneumoniae (ATCC 700603), Pseudomonas aeruginosa (ATCC 15442) e Acinetobacter baumannii (ATCC 19606).

A placa foi incubada por 24 horas a $37^{\circ} \mathrm{C}$. Além disso, foram adicionados controles de esterilidade do meio e dos extratos e de viabilidade bacteriana. Após o período de incubação foi adicionado $30 \mu \mathrm{L}$ de resazurina $0,02 \%$ e realizada a leitura a 
600nm. A Concentração Inibitória Mínima (CMI) foi definida como sendo a menor concentração do extrato capaz de inibir o crescimento bacteriano. Além disso, foi definida o IC $90 \%$ (concentração inibitória de $90 \%$ da população bacteriana).

\section{RESULTADOS}

Neste estudo, foram testados os extratos hexânico, metanólico e aquoso de Ilex paraguariensis, sendo que apenas os extratos hexânico e aquoso foram ativos com CMI entre $25 \mu \mathrm{g} / \mathrm{mL}$ e $200 \mu \mathrm{g} / \mathrm{mL}$, respectivamente, para todas as espécies bacterianas avaliadas.

O presente estudo de atividade antimicrobiana in vitro demonstrou que os extratos inibiram o crescimento de bactérias gram-positiva e gram-negativas. Sendo que, o extrato que apresentou melhor inibição para as cepas estudadas foi o extrato aquoso (CMI $25 \mu \mathrm{g} / \mathrm{mL})$.

O extrato aquoso de Ilex paraguariensis apresentou melhor atividade antimicrobiana frente a $S$. aureus $(\mathrm{IC} 90 \%=18,532 \mu \mathrm{g} / \mathrm{mL})$ quando comparada com as demais espécies bacterianas avaliadas, cujo IC $90 \%$ foi de $151,09,82,70$ e 34,40 para $K$. pneumoniae, A. baumanni e P. aeruginosa, respectivamente.

Já o extrato hexânico frente a A. baumanni apresentou a melhor IC90\% $(99,60 \mu \mathrm{g} / \mathrm{mL})$ quando comparada com $K$. pneumoniae $(166,72 \mu \mathrm{g} / \mathrm{mL})$, P. aeruginosa $(125.68 \mu \mathrm{g} / \mathrm{mL})$ e $S$. aureus $(105,30 \mu \mathrm{g} / \mathrm{mL})$.

Tabela 1. Concentração mínima inibitória das bactérias gram-positiva e gram-negativa pelos tratamentos dos extratos de Ilex paraguariensis.

\begin{tabular}{|c|c|c|c|}
\hline Cepas & & $\begin{array}{c}\text { Extratos (CMI } \\
\mu \mathrm{g} / \mathrm{mL})\end{array}$ & \\
\hline 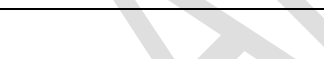 & Hexânico & Metanólico & Aquoso \\
\hline $\begin{array}{l}\text { Staphylococcus } \\
\text { aureus }\end{array}$ & $200 \mu \mathrm{g} / \mathrm{mL}$ & $200 \mu \mathrm{g} / \mathrm{mL}$ & $25 \mu \mathrm{g} / \mathrm{mL}$ \\
\hline $\begin{array}{l}\text { Klebsiella } \\
\text { pneumoniae }\end{array}$ & $200 \mu \mathrm{g} / \mathrm{mL}$ & $200 \mu \mathrm{g} / \mathrm{mL}$ & $200 \mu \mathrm{g} / \mathrm{mL}$ \\
\hline $\begin{array}{l}\text { Acinetobacter } \\
\text { baumannii }\end{array}$ & $100 \mu \mathrm{g} / \mathrm{mL}$ & $200 \mu \mathrm{g} / \mathrm{mL}$ & $50 \mu \mathrm{g} / \mathrm{mL}$ \\
\hline $\begin{array}{l}\text { Pseudomonas } \\
\text { aeruginosa }\end{array}$ & $200 \mu \mathrm{g} / \mathrm{mL}$ & $200 \mu \mathrm{g} / \mathrm{mL}$ & $100 \mu \mathrm{g} / \mathrm{mL}$ \\
\hline
\end{tabular}




\section{DISCUSSÃO}

A família Aquifoliaceae abrange mais de 400 espécies do gênero Ilex, algumas destas já foram relatadas na literatura demonstrando atividade antimicrobiana frente a diversas bactérias gram-positivas e gram-negativas. A Quercus ilex encontrada peculiarmente no Marmara, Egeu e Turquia apresentou atividade antimicrobiana contra sete cepas diferentes com CMI entre $125-500 \mu \mathrm{g} / \mathrm{mL}^{18-20}$. Ilex integra, distribuída à beira-mar em todo o Japão, Taiwan e China, demonstrou atividade antimicrobiana significativa contra bactérias e fungos filamentosos ${ }^{21}$, já as Ilex latifolia e Ilex Kudingcha, tradicional em diferentes áreas da China, foram caracterizadas com atividade antimicrobiana devido aos seus compostos bioativos ácidos fenólicos, flavonóides e os óleos essenciais presente na mesma ${ }^{22-23}$.

Os extratos de Ilex paraguariensis demonstram diferentes atividades inibitórias para os microrganismos estudados, o que pode ser atribuído a variação da composição química de cada extrato. Os estudos divergem sobre quais compostos podem contribuir para a atividade antimicrobiana e se, estes compostos, podem ter efeitos aditivos ou sinérgicos quando utilizados em combinação. Os principais compostos encontrados nos extratos de Ilex paraguariensis que podem contribuir para sua atividade antimicrobiana incluem o ácido caféico, cafeína, ácido clorogênico, kaempferol, quercetina, ácido quínico, rutina e teobromina ${ }^{4,24}$.

A ação antimicrobiana contra bactérias gram-positivas pode ser compreendida por estas apresentarem parede celular quimicamente menos complexa, com menor teor lipídico e ausência de membrana celular externa em comparação às gram-negativas ${ }^{25-26}$. Porém, Haraguchi et al. (1999) sugerem que os triterpenos encontrados nas plantas do gênero Ilex geram mudança na permeabilidade da membrana, resultando na alteração da membrana lipídica do microrganismo, sendo essa a razão da atividade antimicrobiana.

Diante dos resultados obtidos pelo presente trabalho, o qual evidenciou ação antimicrobiana dos extratos hexano e aquoso de Ilex paraguariensis frente à bactéria gram-positiva Staphylococcus aureus, pode-se inferir que ambos os extratos, possivelmente, expressem capacidade de inibir outros microrganismos gram-positivos assim como a bactéria gram-positiva Staphylococcus aureus do presente estudo.

O estudo realizado por Rempe et al. (2015) corrobora com estes achados demonstrando ação antimicrobiana do extrato aquoso de Ilex paraguariensis frente à bactéria gram-positiva Staphylococcus aureus. Assim como Martin et al. (2013) com diferentes extratos das folhas de Ilex paraguariensis (metanólico e etanólico). E, 
Girolometto et al. (2009) evidenciam a mesma associação com os extratos etanólico e hidroalcoólico de Ilex paraguariensis.

Alguns autores relatam que bactérias gram-negativas são menos suscetíveis à ação antimicrobiana ${ }^{29-30}$, porém o presente estudo encontrou tal atividade contra as bactérias Klebsiella pneumoniae, Pseudomonas aeruginosa e Acinetobacter baumannii. Isto pode ser explicado devido aos polifenóis encontrados no extrato hexânico de Ilex paraguariensis (em média uma quantidade de $92 \mathrm{mg}$ ), tais como o ácido caféico e clorogênico que agem, principalmente, contra bactérias gram-negativas rompendo a membrana celular dessas bactérias ${ }^{31}$. Além de outros numerosos fitoquímicos ativos identificados no extrato aquoso de Ilex paraguariensis, entre eles, as xantinas (cafeína e teobromina), os flavonóides (quercetina e kampferol), aminoácidos, minerais (P, Fe, e $\mathrm{Ca})$, e vitaminas $(\mathrm{C}, \mathrm{B} 1 \text { e B2})^{32,33}$.

Não há consenso na literatura com relação à atividade antimicrobiana da Ilex paraguariensis e as bactérias gram-negativas. Porém, o presente trabalho encontrou atividade antimicrobiana dos extratos hexânico e aquoso de Ilex paraguariensis, nos quais demonstraram inibição para todas as bactérias gram-negativas Pseudomonas aeruginosa, Acinetobacter baumannii e Klebsiella pneumoniae.

Alguns autores relatam a associação da atividade antimicrobiana com diferentes extratos de Ilex paraguariensis frente bactérias gram-negativas. Em estudo De Biasi et al. (2009) evidenciaram atividade antimicrobiana com extrato hidroalcoólico de Ilex paraguariensis frente à bactéria Pseudomonas aeruginosa $(\mathrm{CMI}=100 \mathrm{mg} / \mathrm{mL})$, resultado igual ao do presente trabalho $(\mathrm{CMI}=100 \mathrm{mg} / \mathrm{mL})$. Os achados demonstrados por Carelli et al. (2011) divergem, parcialmente, do presente trabalho, pois descrevem atividade antimicrobiana da bactéria Pseudomonas aeruginosa $(\mathrm{CMI}=100 \mathrm{mg} / \mathrm{mL})$, porém não encontraram atividade frente à cepa Acinetobacter baumannii enquanto os extratos hexano $(\mathrm{CMI}=100 \mathrm{mg} / \mathrm{mL})$ e aquoso $(\mathrm{CMI}=50 \mathrm{mg} / \mathrm{mL})$ de Ilex paraguariensis apresentam inibição para ambas bactérias do presente estudo. Bittencourt-Junior et al. (2012) reportaram não haver atividade inibitória do extrato hidroalcoólico de Ilex paraguariensis frente à bactéria Klebsiella pneumoniae, divergindo do identificado pelos extratos hexano $(\mathrm{CMI}=200 \mathrm{mg} / \mathrm{mL})$ e aquoso $(\mathrm{CMI}=$ $200 \mathrm{mg} / \mathrm{mL}$ ) neste trabalho.

A utilização da Ilex paraguariensis como um antimicrobiano é um conceito relativamente novo ${ }^{36}$ e ainda não foi completamente estudado e analisado. Portanto, os achados do presente estudo reforçam a importância da Ilex paraguariensis como uma 
fonte promissora de pesquisa para novos agentes antimicrobianos naturais. Isto, principalmente com relação ao extrato hexânico de Ilex paraguariensis, devido à escassez de estudos na literatura com esse tipo de extrato, e também devido a elevada atividade antimicrobiana encontrada no mesmo. Estes extratos são possíveis candidatos cuja atividade antimicrobiana poderá contribuir para o tratamento de doenças infecciosas causadas tanto por bactérias gram-positivas quanto negativas.

\section{REFERÊNCIAS}

1. Boomsma J, Jensen A, Meyling N, et al. Evolutionary interaction networks of insect pathogenic fungi. Annu Rev Entomol 2014;59:467-485. DOI: https://www.doi.org/10.1146/annurev-ento-011613-162054

2. Bracesco N, Sanchez AG, Contreras V, et al. Recent advances on Ilex paraguariensis research: Minireview. J Ethnopharmacol 2011; 136(3): 378-384. DOI: https://www.doi.org/10.1016/j.jep2010.06.032

3. Heck CI, Schmalko M, de Mejia EG, et al. Effect of growing and drying conditions on the phenolic composition of mate teas (Ilex paraguariensis). J Agric Food Chem 2008;56(18):8394-8403. DOI: https://www.doi.org/ 10.1021/jf801748s.

4. Burris KP, Davidson PM, Stewart CNJr, et al. Antimicrobial activity of yerba mate (Ilex paraguariensis) aqueous extracts against Escherichia coli O157:H7 and Staphylococcus aureus. J Food Sci 2011;136(3): 378-384. DOI: https://www.doi.org/10.1111/j.1750-3841.2011.02255.x

5. Fagundes A, Danguy LB, Schmitt V, et al. Ilex paraguariensis: compostos bioativos e propriedades nutricionais na saúde. RBONE 2015;9(53):213-222.

6. Martin JGP, Porto E, Alencar SM De, et al. Antimicrobial activity of yerba mate (Ilex paraguariensis St. Hil.) against food pathogens. Rev Argent Microbiol 2013;45(2):93-98. DOI: https://www.doi.org/10.1016/s0325-7541(13)70006-3

7. Mendes LPM, Maciel KM, Vieira ABR, et al. Atividade Antimicrobiana de Extratos Etanólicos de Peperomia pellucida e Portulaca pilosa. Rev Ciênc Farm Básica Apl 2011;32(1):121-5.

8. Santos PO, Melo PO, Trindade DLFM, et al. Investigação da atividade antimicrobiana do látex da mangabeira (Harcomia speciosa GOMES). Rev Bras Plantas Med 2007;.9(2):108-111.

9. Carvalho HHC, Wiest JM, Greco DP. Atividade antibacteriana e a preditividade do condimento Artemisia dracunculus Linn. (Asteraceae), variedade inodora -estragão frente a Salmonella sp. Food Sci. Technol. 2006;26(1):75-79.

10. Lima MRF, Ximenes CPA, Luna JS, et al. The antibiotic activity of some Brazilian medicinal plants. Rev Bras Farmacogn 2006;16: 300-306. DOI: https://www.doi.org/10.1590/S0102-695X2006000300004 
11. Walsh FM, Amyes SG. Microbiology and drug resistance mechanisms of fully resistant pathogens. Curr Opin Microbiol 2004;7(5):439-444. DOI: https://www.doi.org/10.1016/j.mib.2004.08.007

12. Montalvo CL, Boulogne I, Suárez JG. A screening for antimicrobial activities of Caribbean herbal remedies. BMC Complementary and Alternative Medicine 2013;13(126):2-9. DOI: https://www.doi.org/10.1186/1472-688213-126

13. Davies J, Davies D. Origins and Evolution of Antibiotic Resistance. Microbiol Mol Biol Rev 2010;74(3):417-433. DOI: https://www.doi.org/10.1128/MMBR.0001610

14. Mahamoud A, Chevalier J, Alibert-Franco S, et al. Antibiotic efflux pumps in Gram-negative bacteria: the inhibitor response strategy. J Antimicrobial Chemotherapy 2007; 59:1223-1229 DOI: https://www.doi.org/10.1093/jac/dkl493

15. Etkin N. Perspectives in Ethnopharmacology: forging a closer link between bioscience and traditional empirical knowledge. J Ethnopharmacology 2001;76:177182.

16. Hongpattarakere T, Johnson EA. Natural antimicrobial components isolated from Yerba Maté (Ilex paraguariensis). Food Research Institute 1999;11(3):42-48.

17. Gonzalez-Gil F, Diaz-Sanchez S, Pendleton S, et al. Yerba mate enhances probiotic bacteria growth in vitro but as a feed additive does not reduce Salmonella Enteritidis colonization in vivo. Poultry Science 2014;93:434-440. DOI: https://www.doi.org/10.3382/ps.2013-03339

18. Karioti A, Sokovic M, Ciric A, et al. Antimicrobial properties of Quercus ilex L. proanthocyanidin dimers and simple phenolics: evaluation of their synergistic activity with conventional antimicrobials and prediction of their pharmacokinetic profile. J Agric Food Chem 2011;59(12):6412-22. DOI: https://www.doi.org/10.1021/jf2011535.

19. Berahou A, Auhmani A, Fdil N, et al. Antibacterial activity of Quercus ilex bark's extracts. J Ethnopharmacol 2007;112(3):426-429. DOI: https://www.doi.org/10.1016/j.jep.2007.03.032

20. Gulluce M, Adiguzel A, Oqutçu H, et al. Antimicrobial effects of Quercus ilex L. extract. Phytother Res 2004;18(3):208-211. DOI: https://www.doi.org/10.1002/ptr.1419

21. Haraguchi H, Kataoka S, Okamoto S, et al. Antimicrobial triterpenes from ilex integra and the mechanism of antifungal action. Phytother Res 1999;13(2):151-156. DOI: $\quad$ https://www.doi.org/10.1002/(SICI)1099-1573)19903)13.2<151::AIDPTR391>3.0CO;2-C

22. Jiang JM, Wang $\mathrm{B}, \mathrm{Xu} \mathrm{SB}$, et al. Research on the antibacterial activity of Kudingcha. Pharm Clin Chin Mat Med 2001;17:18-19. 
23. Li L, Xu JL, Xiao PG. The large-leaved Kudingcha (Ilex latifolia Thunb and Ilex kudingcha C.J. Tseng): a traditional Chinese tea with plentiful secondary metabolites and potential biological activities. J Natural Med 2013;67(3):425-437. DOI: 10.1007/s11418-013-0758-z.

24. Heck CI, Mejia EG. Yerba Mate Tea (Ilex paraguariensis): a comprehensive review on chemistry, health implications, and technological considerations. J Food Sci 2007;72:138-151. DOI: https://www.doi.org/10.1111/j.1750-3841.2007.00535.x

25. Srinisavasan D, Nathan S, Suresh T. Antimicrobial ativity of certain Indian medicinal plants used in folkloric medicine. J Ethnopharmacology 2001;74(3):217-220. DOI: https://www.doi.org/10.1016/S0378-8741(00)00345-7

26. Carelli G, Macedo SMD, Valduga AT, et al. Avaliação preliminar da atividade antimicrobiana do extrato de erva-mate (Ilex paraguariensis A. St. - Hil.) obtido por extração com CO2 supercrítico. Rev Bras P1 Med 2011;13(1):110-115.

27. Rempe CS, Burris KP, Woo HL, et al. Computational Ranking of Yerba Mate Small Molecules Based on Their Predicted Contribution to Antibacterial Activity against Methicillin-Resistant Staphylococcus aureus. Plos ONE 2015;10(5):1-18. DOI: https://www.doi.org/10.1371/journal.pone.0123925

28. Girolometto G, Avancini CAM, Carvalho HHC, et al. Atividade antibacteriana de extratos de erva mate (Ilex paraguariensis A.St.-Hil.). Rev Bras Plantas med 2009;11(1):49-55. DOI: https://www.doi.org//10.1590/S1516-05722009000100009

29. Kubo I, Muroi H, Himejima M. Antibacterial activity against Streptococcus mutans of mate tea flavor components. J Agr Food Chem 1993;41:107-111.

30. Daglia M, Tarsi R, Papetti A, et al. Antiadhesive effect of green and roasted coffee on Streptococcus mutans' adhesive properties on saliva-coated hydroxyapatite beads. J Agr Food Chem 2002;50:1225-1229. DOI: https://www.doi.org/10.1021/jf010958t

31. Dall'Orto VC. Comparison of tyrosinase biosensor and colorimetric method for polyphenol analysis in different kinds of teas. 2005;28:19-33. DOI: https://www.doi.org/10.1081/AL-200043435

32. Pomilio AB, Trajtemberg S, Vitae AA. High-performance capillary electrophoresis analysis of Mate infusions prepared from stems and leaves of Ilex paraguariensis using automated micellar electrokinetic capillary chromatography. Phytochem Anal 2002;13:235-241. DOI: https://www.doi.org/10.1002/pca.647

33. Zaporozhets OA, Krushynska OA, Lipkovska NA, et al. A new test method for the evaluation of total antioxidant activity of herbal products. J Agric Food Chem 2004;52:21-25. DOI: https://www.doi.org/10.1021/jf0343480

34. De Biasi B, Grazziotin NA, Hofmann AE Jr. Atividade antimicrobiana dos extratos de folhas e ramos da Ilex paraguariensis A. St.-Hil., Aquifoliaceae. Braz J 
Pharmacognosy 2009;19(2B):582-585. DOI: https://www.doi.org/10.1590/S0102695X2009000400013

35.Bittencourt-Junior FF, Santos P, Mello F, et al. Study of antibacterial activity of hidroalcoholic extract of Ilex Paraguariensis. Interbio 2012;6(2):48-54.

36.Racanicci AMC, Allesen-Holm BH, Skibsted LH. Sensory evaluation of precooked chicken meat with mate (Ilex paraguariensis) added as antioxidant. Eur Food Res Technol 2009;229:277-280. DOI: https://www.doi.org/10.1007/s00217-009-1052-X 